\title{
A ESCRIBIR A LA VILLA. CLERECÍA URBANA, ESCRIBANOS DE CONCEJO Y NOTARIOS PÚBLICOS EN LA ASTURIAS DEL SIGLO XIII ${ }^{1}$
}

\author{
GO TO TOWN FOR WRITING. URBAN CLERICS, COUNCIL'S SCRIBES \\ AND NOTARIES PUBLIC IN $13^{\mathrm{TH}}$ CENTURY ASTURIAS
}

\author{
Miguel Calleja-Puerta \\ Universidad de Oviedo \\ mcalleja@uniovi.es
}

RESUMEN: La concentración de la producción de escrituras en cabeceras urbanas es uno de los fenómenos característicos del siglo XIII castellano, que acompaña al proceso general de urbanización del reino. Pero a pesar de que ya fuera explorada desde hace casi treinta años por algunos autores, la relación entre escribanos de concejo y notarios públicos en la Corona de Castilla sigue siendo poco conocida y por lo tanto permanece como una incógnita de los procesos políticos y culturales de la época. El propósito de este artículo es trazar el proceso de aparición de escribanos de concejo en el territorio asturiano de esa centuria y explicar su pronta desaparición en beneficio de los escribanos públicos como un reflejo de la voluntad regia de monopolizar la fe pública en la producción de documentos privados.

PALABRAS ClAVE: Escribanos de concejo, notariado público, sellos diplomáticos, Asturias.

ABSTRACT: The concentration of diplomatic writing in towns is one of the main topics of the $13^{\text {th }}$ century in Castille and it grows besides the urbanization of the kingdom. Even though the relationship between council's scribes and notaries public in medieval Castille remains quite unknown. The aim of this paper is to draw the emergence of council's scribes in the territory of Asturias, and subsequently to explain their early replacement by notaries public. This process is considered as a reflect of the king's will to control the production of private charters.

KEYWORDS: Council's scribes, notaries public, diplomatic seals, Asturias.

1. Trabajo realizado en el marco del proyecto de investigación Escritura y ciudad en la Corona de Castilla (siglos XIII-XVII), ref. HAR2012-32298. Ministerio de Economía y Competitividad. Abreviaturas utilizadas: $\mathrm{ACO}=$ Archivo de la Catedral de Oviedo; $\mathrm{AHN} . \mathrm{Cl}=$ Archivo Histórico Nacional, Clero; AMSPO, FSV = Archivo del Monasterio de San Pelayo de Oviedo, Fondo de San Vicente. 


\section{UNA ARRAIGADA TRADICIÓN DIPLOMÁTICA}

La producción de escrituras que reflejan contratos entre particulares en el noroeste peninsular es una de las herencias del mundo antiguo que no se interrumpió en la Alta Edad Media. En esa época, Asturias era una tierra pobre sin centros urbanos propiamente dichos más allá de la corte ovetense. Sin embargo, aquella sociedad rural parece haberse interesado bastante por la producción de escrituras de aplicación de derecho. El original de archivo más antiguo que se conserva en territorio peninsular, fechado en 803, procede del monasterio de Libardón, uno más entre los muchos que se extendían por todo el territorio. De un modo no muy distinto a lo que representaba el núcleo de Oviedo para los reyes de Asturias, estas entidades eran entonces iglesias rurales supeditadas con frecuencia a grupos familiares que los empleaban como centro de poder. Algunos de los presbíteros o diáconos que las servían eran letrados y con cierta frecuencia redactaban documentos, para sus señores y para el resto de la comunidad.

Por encima de todos ellos estaba la ciudad de Oviedo. Exageran las crónicas del siglo IX cuando afirman que Alfonso II restauró allí la corte de Toledo: no tuvieron una cancillería desarrollada a su servicio, y el Oviedo altomedieval solo es urbano en cuanto centro ceremonial y de poder de un reino en formación, mas no por su entidad poblacional o su diversificación económica. Pero sí había un nuevo obispado, y en su entorno los canónigos de San Salvador y los monjes de San Vicente crearon un nuevo e importante centro de escritura llamado a tener fortuna. En los siglos siguientes muchos diplomas recuerdan la condición clerical de sus autores materiales: el abad Ramiro del monasterio de San Vicente en 1057 y 1067, el presbiter et monachus Gonzalo a partir de 1109, y muy especialmente el monje Domingo, cuya elegante escritura visigótica domina el panorama de los documentos solemnes de la Asturias de mediados del siglo XII. Cuando la escritura carolina fue extendiéndose en los documentos asturianos, por aquellas mismas décadas, monjes y canónigos fueron de nuevo los protagonistas del cambio: el exorcista Pelayo en 1144-6, o el canónigo Juan Fernández, entre 1155 y $1179^{2}$.

Pero más allá de los clérigos de Oviedo había en la Asturias altomedieval un extenso grupo de escribanos que trabajaba a nivel local. En ocasiones no consignan su nombre al final de los documentos, y no es raro que no declaren su posible condición clerical $^{3}$. Pero la frecuencia con que ésta se recuerda permite pensar que estaba bastante generalizada entre los amanuenses y que, como es común en el occidente medieval, la redacción de documentos era tarea generalmente vinculada a los eclesiásticos.

2. M. Calleja Puerta. "De la visigótica a la carolina en los documentos del archivo de San Vicente de Oviedo: escritura de Dominicus y Pelagius”. En J.A. Fernández Flórez y S. Serna (coords.). Paleografia I. La escritura en España hasta 1250. Burgos, 2008, pp. 189-200.

3. Algo similar a lo registrado en la documentación portuguesa por M.J. Azevedo Santos. "Os clérigos-notários em Portugal (séculos XI-XII)". En Estudos de Diplomática Portuguesa. LisboaCoimbra, 2001, pp. 75-91 y p. 77. 


\section{LA PRODUCCIÓN DE DOCUMENTOS EN LOS PRIMEROS NÚCLEOS} URBANOS (S. XII)

Hay que esperar a las inmediaciones del 1100 para ver un primer despegue urbano en la región. En el contexto de un reino en expansión los núcleos de Oviedo y Avilés reciben fuero de Alfonso VI, y contemplan a lo largo del siglo XII un primer desarrollo urbano que pasa por la instalación de un importante contingente de población franca y el establecimiento de redes comerciales cada vez más estables, por tierra y por mar.

Sin embargo, en estas décadas pocas cosas parecen cambiar en el ámbito de la producción diplomática. Es cierto que no hemos conservado ni un solo documento otorgado por uno $\mathrm{u}$ otro concejo en todo el siglo $\mathrm{XII}^{4}$, y que lo preservado responde en su práctica totalidad a transferencias de propiedades inmuebles en ámbito urbano. Sea como fuere, con las evidencias disponibles solo es posible afirmar que en los primeros tiempos de la urbanización los eclesiásticos siguieron siendo autores habituales de los documentos, o al menos de aquéllos más solemnes.

El caso más evidente es el de la villa de Avilés. Alfonso VII revalidó y quizá amplió en 1155 los fueros de los que disfrutaban los avilesinos. Y lo hizo mediante un documento extracancilleresco para cuya redacción se recurrió a un escribano local, el presbítero Suero, que quizá representaba los intereses patrimoniales de San Vicente de Oviedo en la cercana iglesia de Santa Eulalia de Lloredo ${ }^{5}$ Más allá de eso, sin embargo, la escasez de los documentos conservados imposibilita conocer lo que ocurre en la villa avilesina hasta el segundo tercio del siglo XIII.

Oviedo representa el caso opuesto. Nada sabemos sobre la génesis diplomática de su fuero ${ }^{6}$, pero al contrario se han conservado decenas de documentos redactados en la ciudad a lo largo del siglo XII. Las instituciones eclesiásticas que los atesoran solían encargarse igualmente de su redacción, y en ellos predominan las transacciones relativas a un dilatado entorno rural. Pero el desarrollo urbano se atisba en unos pocos pergaminos, en las referencias a una comunidad que se abstrae como concilio... ante omnes bonos, gobernada por oficiales propios ${ }^{7}$. Y se acentúa en las suscripciones de personas con nombres nuevos ${ }^{8}$, y en la aparición,

4. Una interesante referencia en X. Viejo. "Noticia d'un vecindariu d'Uviéu del sieglu XII", Revista de Filoloxía Asturiana 6-8 (2006-2008), pp. 467-473.

5. C. del Camino Martínez. "Escritura y elaboración formal de los Fueros de Avilés". En J.I. Ruiz de la Peña, M.J. Sanz Fuentes y M. Calleja Puerta (eds.). Los fueros de Avilés y su época. Oviedo, 2012, pp. 405-430; M. Calleja Puerta. "El fuero de Avilés de 1155, original extracancilleresco de Alfonso VII". Ibid., pp. 431-461.

6. Conocido a través de la confirmación de Fernando IV en 1295, la suscripción de Giraldo permite creer que fue elaborado en la cancillería. Lo edita C. Miguel Vigil. Colección históricodiplomática del ayuntamiento de Oviedo. Oviedo, $1889, \mathrm{n}^{\circ} 1$.

7. P. Floriano Llorente. Colección diplomática del monasterio de San Vicente de Oviedo. Oviedo, $1968, \mathrm{n}^{\circ}$ 149. En el mismo año 1115, otra escritura roborada in Ovedao recoge el nombre de Robert, iudice de illos francos (ibid., $\mathrm{n}^{\circ} 151$ ). En 1142, otra suscripción aparece como aliorum multorum bonorum hominum quorum concilii de Oveto (ibid., $\mathrm{n}^{\mathrm{o}} 207$ ).

8. Ya sea por la propia naturaleza del nombre-Guillermo, Geles, Guionet, Renalt, Emerinus- , por la indicación de procedencia -Gallego, de Allariz, de Arbolio, de Babilonia, Franca-, o por sis- 
aún muy esporádica, de diplomas que describen un espacio progresivamente urbanizado?

En 1208, un último y excepcional ejemplo ratifica la lentitud de las transformaciones. Se trata de la venta de una propiedad rural entre particulares redactada por un tal Petrus Abbas, presbiter ${ }^{10}$ que especifica que ista carta fuit roborata in illo mercado de Vomalo. En sus tres columnas de confirmantes se mezcla una docena de milites de procedencia diversa con un puñado de individuos de antroponimia franca que son frecuentes en los documentos ovetenses coetáneos: Juan Guión, don Goszberte, Pacho, Giral Gros, Domingo Vasallo. En definitiva, parecemos encontrarnos ante uno de los mal conocidos mercados rurales anteriores a la expansión urbana en el reino, que periódicamente congregaban a la población rústica y que lo mismo servían para la adquisición de las mercaderías traídas presumiblemente por aquellos comerciantes ovetenses, que para la redacción pública de documentos o la impartición de justicia, como presupone el hecho de que García Manzaneda figure calificado como iudice ${ }^{11}$.

\section{Consolidación URBANA Y TRANSFORMACIONES EN EL PRIMER TERCIO DEL SIGLO XIII}

A principios del siglo XIII, sin embargo, se producen algunas novedades que avanzan en el camino de la consolidación urbana y de la constitución de ciudades y villas como centros de redacción de documentos.

Oviedo y Avilés progresan hacia su consolidación como centros políticoadministrativos. Alfonso IX aparece como figura esencial del fortalecimiento institucional del concejo ovetense ${ }^{12}$ : le otorga facultad de elegir a los magistrados locales, dispone la construcción de la cerca, regula la celebración del mercado semanal y por último le cede por alfoz la tierra de Nora a Nora ${ }^{13}$. Como correlato de este proceso, coincidiendo con lo que ocurre en otras muchas localidades del reino, el concejo de Oviedo se dota de un sello del que conocemos una primera mención en $1231^{14}$.

temas de denominación ajenos a la tradición local -Guilielmo de illa Barba, Guilielmus de illa Tenda, Petrus de la Tenda, Pelagius Bezerra, Pelagius de Ogo, Iohannes de la Rua, Rodericus Farbalot, Stephanus Garin-, el caso es que las suscripciones de los burgueses de Oviedo se hacen notar en varios ejemplos de la segunda mitad del siglo XII (Floriano Llorente. San Vicente, nos. 217, 251, 289, 290).

9. Ibid., nos. 236 y 263.

10. M.J. Sanz Fuentes y J.I. Ruiz de la Peña. Colección diplomática del monasterio de San Vicente de Oviedo (siglos XIII-XV). I.1: 1201-1230. Oviedo, 1991, $\mathrm{n}^{\circ} 15$.

11. P. Martínez Sopena. "El mercado en la España cristiana de los siglos XI y XII", Codex Aquilarensis 13 (1998), pp. 121-142.

12. J.I. Ruiz de la Peña . El comercio ovetense en la Edad Media. Oviedo, 1990, pp. 42-44.

13. Miguel Vigil. Ayuntamiento de Oviedo, $\mathrm{n}^{\circ} 4$.

14. ACO.B.4.-17. Sobre el mismo, M.J. Sanz Fuentes. "Notas acerca del sello del concejo de Oviedo". Asturiensia Medievalia 6 (1991), pp. 171-176. 
En Avilés, donde la información sigue siendo más escasa, se incorporan algunos nuevos artículos a su fuero, que hacia 1230 adquiere su forma definitiva ${ }^{15}$, y la villa parece ganar en centralidad territorial. Así lo sugiere la venta de una propiedad en el territorio de Gozón en 1223 que, aunque redactada por el monachus et presbiter Alfonso, fuit roborata in concilio de Abiliés coram multis bonis hominibus ${ }^{16}$ : es el primer caso documentado en que la villa, que había empezado siendo una excepción en la extensa tierra de Gozón, comienza a ejercer funciones de cabecera administrativa de aquel extenso realengo ${ }^{17}$.

A diferencia de lo que ocurre con Oviedo, y en menor medida en Avilés, las pueblas nuevas que aparecen en estos años resultan casi desconocidas porque su registro documental es paupérrimo. En los documentos conservados de Alfonso IX apenas hay citas muy circunstanciales a las pueblas regias de Tineo y Llanes ${ }^{18}$. En 1223 el concejo de Tineo establece un acuerdo con el cercano monasterio de San Juan Bautista de Corias, pero ninguno de los dos parece tener sello propio, y recurren a la aposición del sello del rey para mayor firmeza ${ }^{19}$. Peor es lo que ocurre en Pravia, donde hay que esperar a 1230 para encontrar en un contrato entre particulares una fugaz cita al concilio de illa popula tenente Praviam ${ }^{20}$. Al otro lado del Eo, la puebla de Ribadeo había nacido en 1182 y su influencia en tierra asturiana se advierte ya en 1242, cuando ciertas personas se comprometen al pago de una renta al monasterio de Oscos per mediam talegam de burgo y el documento se valida con el sigillum concilii de burgo ${ }^{21}$.

Catedral y monasterios continúan siendo en el primer tercio del siglo XIII las instituciones más pujantes. En Oviedo, tanto el obispo como el cabildo se dotan de sello al menos desde $1230^{22}$, y menudean las referencias a Pedro Martínez, chanceler de episcopo ${ }^{23}$; todo ello supone el arranque definitivo de la cancillería epis-

15. En concreto los artículos 32, 45 y 46 de la edición de M.J. Sanz Fuentes, J.A. Álvarez Castrillón y M. Calleja Puerta. Colección diplomática del concejo de Avilés en la Edad Media (1155-1498). Avilés, 2011, no 1 . Sobre la datación de la versión definitiva del fuero, del Camino Martínez. "Escritura y elaboración formal de los fueros de Avilés", p. 424.

16. Sanz Fuentes y Ruiz de la Peña. San Vicente, $n^{\circ} 74$. Un ejemplo similar, del mismo año, en AHN.Cl.-1596.19. En las décadas anteriores son muchas las decenas de documentos relativos al territorio de Gozón y aparentemente redactados en la zona que no tienen indicios de haberse formalizado en Avilés.

17. El proceso culmina en 1309, cuando Fernando IV supedita la tierra de Gozón a la villa de Avilés, cediéndosela como alfoz (Sanz Fuentes e.a. Concejo de Avilés, $n^{\circ}$ 87).

18. Para Tineo, M. Calleja Puerta. "Un privilegio de Fernando III al concejo de la puebla de Tineo (1232)". En Fernando III y su tiempo (1201-1252). León, 2003, pp. 395-419. Para Llanes, J.I. Ruiz de la Peña. "Epílogo. Los orígenes de la villa de Llanes". En M. Calleja Puerta. El fuero de Llanes. Edición crítica. Oviedo, 2003, p. 184.

19. A.C. Floriano Cumbreño. El libro registro de Corias, 2 vols., Oviedo, 1950, n ${ }^{\circ} 435$.

20. Sanz Fuentes y Ruiz de la Peña. San Vicente, $\mathrm{n}^{\circ} 135$; ocho años más tarde aparece don Ramilo tenente illa popula de Pravia (C. Álvarez Arias. Documentos orixinales del monesteriu de San Vicente d'Uviéu, I (1231-1238). Uviéu, 2008, n 100).

21. J.A. Álvarez Castrillón. Colección diplomática del monasterio de Santa María de Villanueva de Oscos (1139-1300). Oviedo, 2011, n $\mathrm{n}^{\mathrm{O}} 76$.

22. 1230 (ACO.B.4.16, descritos en ACO.B.4.18), 1235 (ACO.A.6.11).

23. 1233 a 1239 (ACO.A.6.6., ACO.A.6.13, AHN.Cl.1597.20; F.J. Fernández Conde, I. Torrente Fernández y G. de la Noval. El monasterio de San Pelayo de Oviedo, I. Oviedo, 1978, nos. 86 y 99, 
copal ovetense ${ }^{24}$. Del mismo modo, el cabildo reordena la administración de sus bienes y la refleja documentalmente a través de la redacción de su primer libro de regla conocido, cuya elaboración data de la década de los treinta del siglo XIII ${ }^{25}$.

Aún en Oviedo, el monasterio de San Vicente avanza en el mismo sentido de mejorar su administración con el recurso a lo escrito. Lo primero que se percibe en los documentos de esta época es que la tipología se enriquece y su expresión diplomática se renueva, de modo que se registran contratos agrarios a partir de $1207^{26}, \mathrm{y}$ también algunos alquileres urbanos al menos desde $1211^{27}$. Su prestigio llega hasta el punto de que el rey Alfonso IX lo escoge como depósito donde se conservará el cuaderno de las pesquisas que ordenó practicar en Asturias en la segunda década del siglo. Monjes como Alfonso Peláez suelen encargarse de la redacción de los documentos en estos años ${ }^{28}$, pero también los vemos actuando al servicio de otras personas y en áreas geográficas alejadas de Oviedo ${ }^{29}$. En fin, el sello se emplea en el monasterio al menos desde $1231^{30}$.

En el ámbito más rural, unos monasterios renovados siguen ejerciendo una indiscutible centralidad y aparentan ser durante un tiempo el centro de las mayores novedades. Los benedictinos de Corias redactan a principios del siglo XIII un cartulario concebido como libro administrativo ${ }^{31}$, mientras que los cistercienses de Oscos inician la serie de sus contratos agrarios en $1208^{32}$. Y aun cuando varios monjes suscriben algunos de los documentos de su archivo, aquí destaca particularmente la figura del abad Gómez, que está al frente del monasterio entre 1231 y 1254. Se conserva una cuarentena de documentos redactados de su mano que lo muestran en itinerancia permanente por las inmediaciones del cenobio ${ }^{33}$. En ellos destacan varios preámbulos alusivos a la importancia de la escritura para la conservación de la memoria ${ }^{34}$, y aparecen instrumentos tan novedosos como cartas de

con referencia a su hijo Alfonso; E.E. Rodríguez Díaz. El libro de la Regla Colorada de la catedral de Oviedo. Oviedo, 1995, n 97).

24. M.J. Sanz Fuentes. "Documento y cancillería episcopal en Oviedo anterior a 1300". En Ch. Haidacher y W. Köfler (eds.). Die Diplomatik der Bischofsurkunde vor 1250. Innsbruck, 1995, pp. $467-482$ у pp. $469-470$.

25. V.M. Rodríguez Villar. Libro de regla del Cabildo (Kalendas I). Estudio y edición del manuscrito $n^{\circ} 43$ de la Catedral de Oviedo. Oviedo, 2001.

26. Sanz Fuentes y Ruiz de la Peña. San Vicente, $\mathrm{n}^{\circ} 11$.

27. Ibid., $\mathrm{n}^{\mathrm{o}} 25$.

28. Por ejemplo en Sanz Fuentes y Ruiz de la Peña. San Vicente, nos. 89, 93.

29. En 1245, la resolución del conflicto entre unos particulares y el monasterio de Eslonza fue validada con el sello del abad y los de los jueces del rey en León, pero su ejecución material correspondió a Fernán Ioán, monge de San Vincenti de Oviedo, qui hanc scripsit (J.M. Ruiz Asencio e I. Ruiz Albi. Colección documental del monasterio de San Pedro de Eslonza. I (912-1300). León, 2007, $\left.n^{\circ} 233\right)$.

30. ACO.B.4.17.

31. Floriano Cumbreño. Corias, cit.

32. Álvarez Castrillón. Oscos, $\mathrm{n}^{\circ} 34$. Siguen muchos en los años siguientes, normalmente como quirógrafos.

33. Ibid., comprendidos entre los nos. 43 y 122.

34. Primero las más convencionales, luego otras más concretas, pero no hay dos iguales (ibid., nos. 47, 54, 61, 73, 96, 99, 105, 106, 107, 110, 111). 
obligación de pago de deudas o relaciones de documentos a modo de inventario, algunas en forma de cuadernillo ${ }^{35}$. No deja de ser curioso que el abad actúe al mismo tiempo como escribano y destinatario, y se observa una preocupación singular en los diversos modos en los que describe su papel: abbate domino Gometio scribente carta...Lupus Vermudi scripsit. Notante abbate Gometio...facta fuit ista carta per manus abbatis ${ }^{36}$. En definitiva, todo indica que es muy consciente del valor de la escritura para la protección del patrimonio monástico, y la emplea de una forma novedosa, con recursos antes desconocidos.

Por añadir otros casos, es ejemplar la veintena larga de documentos mediante los que el monasterio de Cornellana se fue haciendo con sucesivas porciones de la cercana parroquia de Santiago de Villazón a lo largo del siglo XIII ${ }^{37}$. Una decena del período 1226-1249 están suscritos por el mismo escribano, Lorenzo, que nunca indica una posible condición monástica, pero que demuestra en su actividad una estrecha relación con la comunidad: lo mismo redacta sus escrituras en el pórtico de la iglesia de Villazón o en el monasterio de Cornellana, que recorre cuarenta kilómetros hasta Oviedo para escriturar la donación de la parte que poseía el obispo Rodrigo ${ }^{38}$.

En fin, la misma importancia de los monasterios parece advertirse en el oriente de la región cuando vemos que el abad de San Pedro de Villanueva escribe ante el concilio de Santa Maria de Cangas, clericis et laicis, en $1215^{39}$. Por su parte, en la montaña central la colección diplomática de Belmonte llama la atención por su rusticidad $^{40}$, pero aún así esta comarca ingresa también en el ámbito de las zonas documentadas, y su monasterio cisterciense se convierte en centro de escritura donde también se hacen proyectos de cartularización ${ }^{41}$. En fin, otras instituciones eclesiásticas van avanzando en procurarse un sello propio: están documentados el del abad de Cornellana en $1229^{42}$, el del abad de Oscos en $1244^{43}$, el del abad y cabildo de Teverga en $1259^{44}$.

En cualquier caso, y a pesar de la importancia de los escribanos monásticos, que trabajan regularmente fuera de sus comunidades, quedaba un importante espacio en la producción de documentos privados que era cubierto, unas veces, por

35. Respectivamente nos. 101 y 80,86 y 87 .

36. Ibid., nos. 48, 52, 53.

37. Los publica J.I. Fernández de Viana y Vieites. "Pergaminos del monasterio de Cornellana (Asturias) en el archivo de San Payo de Antealtares (Santiago)". Asturiensia Medievalia 4 (1981), pp. 297-399, nos. 1-22.

38. Respectivamente nos. 5, 7, 9 y 10.

39. M.J. Sanz Fuentes. "Documentos del monasterio de San Pedro de Villanueva (ss. XII-XIII)". Estudis Castellonencs 6 (1994-1995), pp. 1333-1342, $\mathrm{n}^{\circ} 2$.

40. Fueron editados hasta 1230 por A.C. Floriano Cumbreño. Colección diplomática del monasterio de Belmonte. Transcripción y estudio. Oviedo, 1960. El resto del siglo XIII fue editado por M. Fernández Mier. Documentos del monesteriu de Balmonte (sieglu XIII). Uviéu, 1995.

41. A. Suárez González. "Partidos de cartularios. Una aproximación arqueológica a los ejemplares pregóticos de Oseira, Belmonte, Valparaíso y Valbuena”. Cistercium 59 (2007), pp. 401-432.

42. Fernández de Viana. "Cornellana", nº 3 .

43. Álvarez Castrillón. Oscos, $\mathrm{n}^{\circ} 76$.

44. Fernández Mier. Balmonte, $\mathrm{n}^{\circ} 34$. 
escribanos anónimos, y en la mayoría de los casos por presbíteros o diáconos que hacían de la escrituración de documentos una actividad regular.

El representante más caracterizado de quienes escriben documentos en la Asturias de la época es el presbítero Pedro Bono, que ejemplifica bien la síntesis entre la tradición de los clérigos notarios y el arraigo urbano de una época nueva. Lo primero que llama la atención es la cantidad de testimonios que se han conservado. $\mathrm{Si}$ en la centuria anterior era raro encontrar la obra de un escribano que se extendiese a unas pocas decenas de documentos, de Pedro Bono han quedado unas 150 piezas autógrafas comprendidas entre 1203 y $1243^{45}$.

Llama igualmente la atención el modo en que se reparte lo rural y lo urbano en su actividad. Pedro Bono parece haber vivido en Oviedo, en el barrio del obispo ${ }^{46}$. Una parte importante de sus pergaminos le sitúan en dicha ciudad, donde es el protagonista principal de la escrituración de inmuebles urbanos, principalmente casas y huertas. Y a la luz de las relaciones de testigos es probable que esté trabajando en Oviedo en muchos documentos que ponen por escrito transacciones sobre bienes repartidos en un radio de unos treinta kilómetros alrededor de la ciudad.

Sin embargo, en las no tan escasas ocasiones donde figura la data tópica, se observa con claridad que Pedro Bono también acude a la llamada de su clientela. Lo hace dentro de la ciudad, ya sea al cabildo de San Salvador, a los monasterios de San Vicente y San Pelayo, o a las iglesias parroquiales ${ }^{47}$. Pero también escribe fuera, bien en diversas localidades del alfoz de Oviedo ${ }^{48}$, bien en territorios limítrofes como los de Siero, Llanera, Candamo o Pravia ${ }^{49}$. Abundando en el mismo sentido, la identidad de algunos testigos hace posible que otros diplomas que no incluyen data tópica se hayan redactado también en localidades rurales más o menos alejadas de Oviedo.

En definitiva, al filo de 1240 se están verificando algunas transformaciones que anuncian el desarrollo de las épocas siguientes. Las principales novedades se advierten en Oviedo, la zona mejor documentada, con un concejo fortalecido que acaba de dotarse de sello. Hay indicios de que avanza en el mismo sentido la villa de Avilés y las pueblas nuevas de Tineo, Llanes, Pravia o Ribadeo. Sin embargo, las instituciones eclesiásticas aún parecen pioneras en la renovación de las prácticas documentales, y destaca el papel tradicional de los clérigos notarios que en la figura de Pedro Bono adquiere un perfil nuevo, inducido por las necesidades de una sociedad urbana. En sus producciones vemos que comienza a entrar la lengua romance, ya sea en la descripción de situaciones o en la aparición de tipos docu-

45. M. Calleja Puerta: "Un escribano ovetense de principios del siglo XIII: el presbítero Pedro Bono", en Orígenes de las lenguas romances en el reino de León, Siglos IX-XII. León, 2004, pp. 465-490.

46. En 1265 se ubica en la rúa de Barredo la casa que foe de don Pedro Bono el escriván (Fernández Conde e.a. San Pelayo, $\left.{ }^{\circ} 117\right)$.

47. Sanz Fuentes y Ruiz de la Peña. San Vicente, nos. 14 y 49; AMSPO. FSV.1045; Fernández Conde e.a. San Pelayo, nos. 48 y 55; AHN.Cl.1597.15.

48. Sanz Fuentes y Ruiz de la Peña. San Vicente, $n^{\circ} 106$; Fernández Conde e.a. San Pelayo, $\mathrm{n}^{\circ}$ 73; AMSPO.FSV.777 y 1054.

49. Sanz Fuentes y Ruiz de la Peña. San Vicente, nos. 14, 41, 42 y 59; Fernández Conde e.a. San Pelayo, $\mathrm{n}^{\circ}$ 78; AHN.Cl.1598.9. 
mentales nuevos ${ }^{50}$; del mismo modo, en las listas de confirmantes aparecen en la tercera década del siglo las referencias a oficios urbanos, llamadas a tener un gran protagonismo en el inmediato futuro. La formulación de los documentos entre particulares, sobre todo aquéllos redactados en Oviedo, sugiere una progresiva formalización por la insistencia en el hecho de que se oyó leer el documento, y la referencia constante a ciertas ceremonias asociadas a los contratos ${ }^{51}$.

Aún así, algunas importantes transformaciones todavía no se han producido. En el ámbito de la justicia, es relevante que en 1230 todavía sea un presbítero quien redacta la resolución de un pleito sustanciado ante los jueces y hombres buenos de Oviedo ${ }^{52}$. Pero en ese mismo año, el obispo y una nutrida representación del cabildo se desplazaban a Santiago de Compostela para acordar con la sede compostelana el pago del Voto de Santiago; y el documento resultante, aunque validado por los sellos de todas las instituciones comprometidas, fue redactado por Martinus Iohannis, notarius concilii Compostellani ${ }^{53}$. Era una de las primeras noticias en Asturias de una institución, la del escribano de concejo, que pronto sería transferida a la ciudad de Oviedo ${ }^{54}$.

\section{LA FUGAZ APARICIÓN DE LOS ESCRIBANOS DE CONCEJO}

En las décadas centrales del siglo XIII, tres factores renuevan el panorama de producción de documentos en las ciudades y villas asturianas ${ }^{55}$. En primer lugar la aparición de los escribanos de concejo; en estrecha relación con ella, la difusión -o revelación documental- de un buen número de sellos concejiles que se suman a los pioneros de hacia 1230; y por último, un factor poco atendido en la historiografía,

50. M.J. Sanz Fuentes y M. Calleja Puerta. "La lengua de los documentos asturianos en los siglos X-XIII: del latín al romance". En La langue des actes. Actes du XIe Congrès internationale de Diplomatique (Troyes, jeudi 11-samedi 13 septembre 2003), en línea, http://elec.enc.sorbonne.fr/CID2003/ calleja-puerta_sanz-fuentes

51. Beber vino, romper un cuenco... también a pagos al concejo en las transacciones.

52. Sanz Fuentes y Ruiz de la Peña. San Vicente, $n^{\circ} 130$.

53. ACO.B.4.16.

54. Sobre su temprano desarrollo en Galicia vid. F. López Alsina. "Galicia en los siglos XII-XIII: notariado, documentos y cultura literaria”. En A.I. Boullón Agrelo (ed.). Na nosa lyngoage galega. A emerxencia do galego como lingua escrita na Idade Media. Santiago de Compostela, 2007, pp. 53-67; y J. D'Emilio. "Writing is the precious treasury of memory. Scribes and notaries in Lugo (1150-1240)". En H. Spilling (ed.). La collaboration dans la production de l'écrit médiéval. Paris, 2003, pp. 379-403.

55. Algunas aproximaciones generales son las de J. Bono Huerta. Historia del Derecho Notarial español, (Vol.I-1). Madrid, 1979, E. Corral García. El escribano de concejo en la Corona de Castilla (siglos XI al XVII). Burgos, 1987. A escala local, vid. por ejemplo los estudios de J.A. Martín Fuertes. "Notarios públicos y escribanos del concejo de León en el siglo XIV". Archivos Leoneses 38 (1984), pp. 7-30; M.J. Sanz Fuentes. "Documento notarial y notariado en la Asturias del siglo XIII", en Notariado público y documento privado: de los orígenes al siglo XIV. En Actas del VII Congreso Internacional de Diplomática, Valencia, 1989, pp. 245-257; M.D. Rojas Vaca: "Los inicios del notariado público en el reino de Castilla. Aportación a su estudio". Anuario de Estudios Medievales 31/1 (2001), pp. 329-395 у p. 334 . 
y que es la presencia creciente de los adelantados y merinos como instancias de producción diplomática.

Una vez descontadas todas las pérdidas documentales, la presencia más evidente es la aparición en Oviedo de un rogatario, Rodrigo Martínez, que suscribe en torno a un centenar de documentos privados entre 1237 y 1262, calificándose insistentemente como escriván del concello ${ }^{56}$, y que pronto empieza a tener una serie de amanuenses a su servicio. A pesar de que la ciudad cuenta con ordenanzas en 1245 y 1262, la figura del escribano de concejo no se regula en ninguna de ellas, y el perfil del oficio solo puede reconstruirse mediante el estudio de su obra conservada.

$\mathrm{Su}$ actividad sigue atendiendo a buena parte del centro de Asturias, aunque ya no es tan evidente su trabajo itinerante como el que se veía en la generación anterior. El área geográfica de su labor se ciñe fundamentalmente a la ciudad de Oviedo y su alfoz, donde lo mismo acude al cabildo de la catedral que al corral de San Tirso, lugar habitual de reunión del concejo, que a domicilios particulares ${ }^{57}$; tampoco faltan documentos relativos a los territorios limítrofes de Llanera, Siero, Langreo, Grado y al algo más alejado de Gozón. El hecho de que algunas de esas transacciones sean negocios entre particulares sin aparente relación con la ciudad de Oviedo subraya el prestigio del escribano. Sin embargo no parece que se haya desplazado a lugares distantes y da la impresión, ante las relaciones de testigos, de que trabaja generalmente en Oviedo. En su actividad predominan las compraventas, si bien se han conservado igualmente donaciones, arrendamientos, pleitos y cartas de arras. No falta entre su clientela el cabildo catedralicio, para quien parece asumir la tarea de redactar los documentos de explotación de su patrimonio ${ }^{58}$.

Aunque el paso al romance es ya casi completo en su obra gráfica y aparecen cláusulas de garantía inéditas hasta entonces ${ }^{59}$, sus documentos mantienen algunos rasgos de la época anterior. Tal es el caso de los preámbulos latinos sobre las bondades de la escritura, la insistencia en la lectura pública del documento en concello, y el recuerdo de haberse suscrito las transacciones bebiendo vino y rompiendo un cacharro: la panniella o tariego ${ }^{60}$. Significativamente, la iussio sigue correspondiendo a los otorgantes que mandan fazer el documento y reconocen sus signos, mientras que el escribano, que también cuenta con signo propio, describe su acción con los tradicionales notuit o scripsit et est testis ${ }^{61}$. En esa escrituración

56. C. de Hoyos González. Rodrigo Martínez, escribano del concejo de Oviedo. Tesis de licenciatura inédita, Universidad de Oviedo, 2013.

57. in cabidro de San Salvador, in pleno capitulo (AHN.Cl.1599.5); en concello en corral de Sancty Tysso, hu esta carta foe otorgada (AHN.Cl.1599.17).

58. Redacta arrendamientos para la catedral en AHN.Cl.1599.6 y 9.

59. AHN.Cl.1599.5.

60. Parecen usos propios de Oviedo, pues no figuran cuando redacta documentos de otras jurisdicciones como se observa en AMSPO.FSV.616 y 1006; AHN.Cl.1599.12), ni siquiera en el alfoz, según ocurre en una venta en Olivares (AMSPO.FSV.689 y 690), o en Mercadín (AMSPO.FSV.1009).

61. En algunos casos incorpora el mandado a su suscripción: Rodrigo Martíniz, escriván del concello, notuit per mandado de Iohan Rodríguiz et est testis (ACO.A.7.1); casos similares en AMSPO. FSV.616 y 1003 . 
se atisba la existencia de dos momentos a través de algunas listas de testigos anotadas en algunos dorsos, que luego se formalizan en la redacción completa del documento ${ }^{62}$.

La naturaleza privada de los documentos conservados debe ser subrayada. En efecto, y a pesar de su habitual fórmula de suscripción, es muy poco lo que se conoce sobre la actividad de Rodrigo Martínez en la redacción de documentos intitulados por el concejo de Oviedo o de documentos del ámbito judicial. Bien al contrario, el registro de fuentes que han llegado a nosotros le muestran prácticamente como el sucesor de Pedro Bono, cuya actividad cesaba en 1243. A partir de ese momento la labor de Rodrigo Martínez se multiplica, y finaliza precisamente en el momento en que va a aparecer en Oviedo el primer notario público de nombramiento real ${ }^{63}$. Por lo tanto, en la obra conservada de Rodrigo Martínez el papel de escribano de concejo se asimila más bien a la figura de redactor de documentos privados para la comunidad y con respaldo del concejo. Con su desaparición de la escena lo que cambiará es la autoridad que lo nombra, que pasa a ser la del rey. Pero en la práctica, los notarios públicos seguirán siendo, como éste, amanuenses que trabajan para la comunidad.

Como se ha indicado, escasa es también la actividad de Rodrigo Martínez en la redacción de documentos que refrendan la solución de algún conflicto, pues se reduce a un par de casos. En 1254, el abad y monjes de San Vicente de Oviedo se avienen con unos particulares en relación a una casa cuya propiedad compartían, y significativamente lo hacen en concello... hu se partió esta carta, y ante dos jueces y dos alcaldes de la ciudad, cuya presencia es excepcional en todos los documentos anteriores ${ }^{64}$. En una avenencia similar fechada dos años después se recuerda qua la carta foe leuda ye partida ye otorgada en cabidro, pero en este caso no hay referencia alguna a alcaldes o jueces ${ }^{65}$.

Finalmente, hay que tener muy en cuenta su actividad al servicio del concejo de Oviedo. Rodrigo Martíniz, escriván del concello, notuit et est testis, es la consabida suscripción con la que cerró en 1257 el contrato por el que el concejo arrendaba a Pedro Giráldiz y a su mujer Marina Martínez la recaudación de las rentas concejiles en el alfoz de Nora a Nora ${ }^{66}$. Pero ése es el único documento concejil conocido al que añadió su nombre: una carta partida a la que los jueces apusieron el sello del concejo, y cuyo tenor alude a otros contratos similares, siempre sellados con el sello pendiente. No en vano éste seguía siendo el elemento principal de validación de los $\operatorname{mismos}^{67}$. En todo caso el análisis gráfico sugiere que aquélla

62. AHN.Cl.1598.11, AHN.Cl.1599.16 y AHN.Cl.1600.2; ya lo advirtió De Hoyos, que los edita con los nos. 2, 68 y 77.

63. O. Rodríguez Fueyo. "Nicolás Yáñez. El paso del prenotariado al notariado en Oviedo en el siglo XIII". En A. Castro Correa e.a. (eds.). Estudiar el pasado. Aspectos metodológicos de la investigación en Ciencias de la Antigüedad y de la Edad Media. Oxford, 2012, pp. 383-391.

64. ACO.A.7.11.

65. AHN.Cl.1599.13.

66. Miguel Vigil, Ayuntamiento de Oviedo, nº 20.

67. Y a él nos atenemos para encuadrarlo dentro de la diplomática concejil. En el mismo sentido, M.J. Sanz Fuentes. "De diplomática concejil castellana en la Edad Media. Una nueva propuesta 
no fue su única actuación al servicio del municipio, y de hecho parece ser el autor material de todos los documentos del concejo de Oviedo que se conservan entre 1243 y 1258 , ya sean arrendamientos de rentas, ordenanzas o avenencias con otros concejos $^{68}$.

$\mathrm{Y}$ es que la plena difusión del sello concejil parece convertirse en un fenómeno de la mayor importancia en las décadas centrales del siglo XIII, y se encuentra que particulares piden habitualmente su aposición a negocios privados para los que buscan el refrendo de la institución concejil ${ }^{69}$. Las ordenanzas del concejo de Oviedo de 1262 dedican un artículo a la regulación de su empleo ${ }^{70}$. Por un lado distinguen la existencia de un sello mayor, y con ello establecen el procedimiento de su aposición en línea con lo que disponía la legislación regia pocos años atrás: sea en poder de dos omnes bonos que non sean justicias, que tengan el uno la una tavla del seello e el otro la otra...; por su parte, noticias de 1264 sitúan el sello menor en manos de los jueces, no del escribano ${ }^{71}$.

Más allá del caso ovetense, todo concurre a que sea difícil documentar la aparición del sello concejil en la Asturias del siglo XIII. Si los documentos se han conservado en muy escaso número, los sellos han sufrido más $\mathrm{y}$, en el caso asturiano, desaparecido por completo; viene a complicar las cosas el hecho de que el anuncio de su aposición parece un fenómeno tardío. Y a pesar de todo, en estos años centrales del siglo comienzan a registrarse noticias de nuevos sellos concejiles, tanto de aquéllos que experimentan el desarrollo de una villa como de los de jurisdicciones que carecen de una cabecera urbana. Es la época en que la legislación alfonsí regula su empleo en los centros urbanos, prescribiendo que debían estar en manos de dos hombres buenos y leales en cada lugar cuyo nombramiento, añaden las Partidas, debía corresponder al monarca ${ }^{72}$. De su pujanza da fe el hecho relativamente frecuente de que se usan para validar negocios privados en los que alguno de los actores documentales ruegan al concejo o a sus jueces su aposición para mayor firmeza.

Así, quedan noticias del sello de Nava en $1252^{73}$. El de Avilés subrayaba su raigambe leonesa al representar en medio dél fegura de navio, e sobrel navío fegura de una cabeça de léon ${ }^{74}$, y encuentra su primera referencia documentada en 1254, cuando los feligreses de Sabugo ruegan su aposición al documento del acuerdo

de clasificación documental". En P. Cherubini y G. Nicolaj (eds.). Sit liber gratus, quem servulus est operatus. Studi in onore di Alessandro Pratesi per il suo $90^{\circ}$ compleanno. Città del Vaticano, 2012, pp. $535-548$ y p. 547.

68. Miguel Vigil, Ayuntamiento de Oviedo, nos. 15, 16 y 24.

69. Por ejemplo el que publica M.J. Sanz Fuentes. "De la vida y de la muerte. Cuatro documentos asturianos del siglo XIII". Revista de Filoloxía Asturiana, 3-4 (2003-2004), pp. 241-254, n 1: E que fosse maes firme, rogamus hio e mia madre a los juizes e a los omnes bonos del concello de Ovedo que feziessent esta karta seelar del seello de so concello en testemunnia de verdat.

70. Las publica Miguel Vigil. Ayuntamiento de Oviedo, nº 29.

71. seello menor del concello de Oviedo, de que son tenedores (AHN.Cl.1600.11bis).

72. Fuero Real, 1.7.3; Partidas, 3.20.2.

73. I. Torrente Fernández. El dominio del monasterio de San Bartolomé de Nava (ss. XIII-XVI). Oviedo, 1982, ap. $\mathrm{n}^{\circ} 6$.

74. Ibid., $\mathrm{n}^{\mathrm{o}} 126$. 
que han alcanzado con el cabildo sobre el patronato de su iglesia de Santo Tomás ${ }^{75}$. El de Tineo está documentado al menos en $1256^{76}$. Y es de suponer que la mayoría de las jurisdicciones concejiles asturianas se hayan dotado del mismo por estas fechas. Muy relevante es el hecho de que también en 1256 tenga sello el pequeño concejo de Sariego ${ }^{77}$, precisamente uno de los que pocos años después fracasaría en su intento de obtener puebla por la oposición de los monasterios de Valdediós y de San Pelayo de Oviedo, y que de hecho ha perdurado como concejo netamente rural hasta la actualidad.

Por debajo de la autoridad de los sellos, la identidad de los escribanos que trabajan al servicio de los nuevos concejos suele permanecer en el anonimato, y solo mediante su participación en la escrituración de contratos privados tenemos noticia de su aparición en algunas nuevas jurisdicciones. En la bien documentada tierra de Grado, Alfonso X fundó en los primeros años de su reinado una puebla que ya en 1256 figura como tenente Pentenno ${ }^{78}$, y por tanto constituida y dotada de ciertos ingresos fiscales. Pues bien, un año más tarde Martín Rodríguez, escriván del concello de la pobla de Grado, comienza a aparecer suscribiendo varios documentos privados, actividad en la que permanece hasta 1269. En el mismo 1256 vemos la suscripción Dominicus, notarius de concilio, notuit al final de una sentencia arbitral que dirimía un conflicto entre el monasterio de Obona y el concejo de Tineo, al que con toda probabilidad estaba vinculado ${ }^{79}$. Algo después, aunque la fecha no es segura, hay noticias de la actuación de otro escrivano del concello de Nava en un acuerdo entre el monasterio de San Bartolomé y el capellán que las monjas acababan de elegir como poseedoras del patronato ${ }^{80}$.

Por último, para comprender esta época en la que se conjuga el desarrollo municipal con la reformulación del poder regio en territorio asturiano, es importante retener el papel de los merinos como representantes de la autoridad real, que constituyen también una importante instancia de producción documental. En la época en que los esfuerzos de la Corona se orientaban definitivamente hacia la Andalucía bética y los monarcas escenificaban las últimas de sus antes asiduas visitas al territorio asturiano, su representación quedó en manos de los merinos, luego de los adelantados mayores. Se constituía así una pirámide en que la cadena de mando va del rey al merino mayor y de éste a sus oficiales territoriales. Y obviamente el vehículo que articulará de forma eficaz sus relaciones no podía ser otro que la escritura, que en sus manos supone el nacimiento de algunas importantes cancillerías menores.

García Rodríguez Carnota es una presencia constante en las fórmulas de expresión de dominio desde la segunda década del siglo XIII, y es interesante subrayar

75. M.J. Sanz Fuentes y M. Calleja Puerta. Litteris confirmentur. Lo escrito en Asturias en la Edad Media, Oviedo, 2005, pp. 285-287.

76. M.J. Sanz Fuentes. "Documentos medievales del monasterio de Santa María de Obona en la Chancillería de Valladolid”. Revista de Filoloxía Asturiana 2 (2002), pp. 155-191 y nº 3.

77. Fernández Conde e.a. San Pelayo, nº 104.

78. AMSPO. FSV.578.

79. Sanz Fuentes. "Obona", n 3.

80. Torrente Fernández. Nava, $\mathrm{n}^{\circ} 8$. 
que este oficial regio dispone de sello de validación al menos desde $1242^{81}$; un año más tarde, el concejo de Nora a Nora le pedía que metiese sus sellos en esta carta por la que arrendaba el cobro de sus derechos ${ }^{82}$. De Gonzalo Morán, que le sucedió en el oficio a partir de 1253, consta también el empleo de sello desde ese mismo año ${ }^{83}$. Era la época en la que nuevas instituciones eclesiásticas se sumaban a la lista de las que disponían de sello ${ }^{84}$, y en la que éste se difundía ya entre dignidades eclesiásticas como el deán ${ }^{85} \mathrm{o}$ algunos $\operatorname{arcedianos}^{86}$.

Pero junto al sello iba una oficina de expedición de documentos cuya formación aún merece un estudio detallado. Es posible que el merino mayor García Rodríguez haya tenido al menos un escribano fijo a su servicio, cuyo nombre se documenta en $1244^{87}$. En 1255, un merino menor intitula un mandato por el que ordena a los jueces de Gozón y a los pescadores que faenan en Luanco que paguen al monasterio de San Vicente el portazgo acostumbrado ${ }^{88}$; en este caso la formalización diplomática de la pieza es ya mucho más pobre. Pero en 1259 Monín Rodríguez, que actúa como merino menor al servicio de Gonzalo Gil, ya emplea sello propio en un pleito sustanciado en Oviedo ${ }^{89}$. Y a partir de los años sesenta, los documentos intitulados por Gutierre Suárez reflejan ya la existencia de un cierto aparato burocrático como aquel de 1262 donde se indica que Don Gutier Suárez la mandó... Estevan Pérez la fyzo scrivir ${ }^{90}$.

Todo sumado, los merinos regios se convierten en autoridad para los actos públicos y las actas que los documentan, y así se entiende la noticia de que en 1261 el monasterio de Belmonte toma posesión de una propiedad por ramo e por cespede quan Gonçalvo Moran, merino del rey, foe en Salas ${ }^{91}$. Más interesante todavía es el hecho de que sean llamados para la escrituración de documentos de particular trascendencia. Gutierre Suárez, adelantado mayor del reino de León, es quien redacta el documento de fundación de la Pola de Allande, una jurisdic-

81. Álvarez Castrillón. Oscos, $\mathrm{n}^{\mathrm{o}} 71$.

82. Miguel Vigil. Ayuntamiento de Oviedo, n ${ }^{\circ}$ 15, de nuevo en 1245, ibid., nº 16, y 1248 (J.A. Fernández Flórez y M. Herrero de la Fuente. Colección documental del monasterio de Santa María de Otero de las Dueñas, II (1109-1300) e índices. León, 2005, nº 577).

83. C. Casado Lobato. Colección diplomática del monasterio de Carrizo, León, 1983, nº 296.

84. Caso de Arbas en 1259 (Miguel Vigil. Ayuntamiento de Oviedo, $\mathrm{n}^{\circ} 25$ ).

85. Al menos desde 1249 (Casado Lobato, Carrizo, $\mathrm{n}^{\circ}$ 253; ACO.B.5.1).

86. Fernández Mier. Balmonte, $\mathrm{n}^{\mathrm{0}} 34$; Fernández Flórez y Herrero de la Fuente. Otero, $\mathrm{n}^{\mathrm{o}} 628$.

87. Así podría concluirse del testimonio de la resolución de un conflicto en la que los contendientes, después de haber recibido consello con don García Rodríguez, mayor merino del rey... ven confirmado el documento resultante por Roy Sánchiz, escriván de don García (ibidem, $\mathrm{n}^{\circ} 549$ ).

88. AMSPO.FSV.1217. Lo editó L. Serrano. Cartulario de San Vicente de Oviedo (781-1200). Madrid, 1929, p. 312.

89. J.I. Ruiz de la Peña. "Facer justicia en una ciudad medieval. El concejo de Oviedo contra la viuda doña Loba", Boletín del Real Instituto de Estudios Asturianos, 146 (1995), pp. 589-602, n 3, descrito como sua carta seellada en el $n^{\circ} 4$.

90. Casado Lobato. Carrizo, $\mathrm{n}^{\circ} 395$.

91. Fernández Mier. Balmonte, $\mathrm{n}^{\circ} 63$. 
ción episcopal del occidente de la región, a la que por supuesto el merino apuso también su sello pendiente ${ }^{92}$.

\section{El impUlso DEFINITIVO A LAS POLAS ASTURIANAS Y LA DIFUSIÓN DEL NOTARIADO PÚBLICO}

En los años sesenta del siglo XIII, la ecuación entre los concejos nacientes y el poder real terminaría resolviéndose a través de los oficiales de escritura. Las ordenanzas de Oviedo de 1262 sugerían la existencia de varios escribanos al servicio del concejo cuando establecían que todo esto sea escripto por uno de nuestros escribanes jurados ${ }^{93}$. Estos, o los escribanos de concejo documentados en otras villas, parecen recibir su autoridad de la comunidad urbana. Por su parte, la implantación territorial de los oficiales del rey no parecen haber encontrado un espacio propio, y lo mismo expiden documentos desde Oviedo, que desde un monasterio como el de Corias, o una puebla fracasada como la de Portiella ${ }^{94}$.

Sin embargo las cosas estaban a punto de cambiar. En Oviedo, Rodrigo Martínez desaparece de la escena para siempre en 1260. Le reemplaza momentáneamente Alfonso Yáñez, documentado en ese año ${ }^{95}$, y luego Juan Pérez, que el 8 de agosto de 1263 aparece recordado como escribano de concejo ${ }^{96}$.

Pero es el autor material de estos dos diplomas quien va a marcar la siguiente etapa de la diplomática ovetense: su nombre, Nicolás Yáñez. Era éste un nieto del presbítero Pedro Bono que, aún en su juventud, había trabajado con asiduidad al servicio del escribano de concejo, en aquella incipiente oficina ${ }^{97}$, y también como escribano independiente. Pero después de tres años sin que sepamos nada de él, Nicolás Yáñez regresó en agosto de ese mismo año 1263; lo hacía con un título nuevo, el de escribano público del rey en Oviedo; y ahora era también capaz de ejecutar una escritura distinta, mucho más avanzada que el modelo gráfico tardocarolino aprendido en la sede ovetense.

Nicolás Yáñez es el primer escribano público de nombramiento real en la ciudad, bastante tardío en el contexto del reino, y como tal desarrolla su actividad

92. Lo edita J.I. Ruiz de la Peña. "Sobre la fundación de la Pola de Allande y su carta puebla". Boletín del Instituto de Estudios Asturianos 68 (1969), pp. 16-19.

93. Miguel Vigil. Ayuntamiento de Oviedo, nº 29.

94. Respectivamente, los ejemplos ya citados que editan Serrano. San Vicente, p. 312, y Álvarez Castrillón. Oscos, n ${ }^{\circ}$ 71. Data de 1253 la escritura de Gonzalo Morán dada en Portiella (Fernández Conde e.a. San Pelayo, $\mathrm{n}^{\circ}$ 96).

95. Nicolao Iohánniz, que la escrivió per mandado de Alfonso Yanes, escriván del concello de Oviedo (S) (ACO.A.8.3).

96. Nicolao notuit per mandado de Iohán Périz, escriván del concello de Oviedo (S) (AHN. C1.1600.9).

97. En 1255, en su primera comparecencia documental, aparece como Nicolao, nieto de don Pedro Bono, escriván que foe, la escrivió per mandado de Roy Martíniz, scriván, so amo (ACO.A.7.13). A partir de entonces, y hasta 1259, trabaja siempre por mandado del escribano de concejo. Desde entonces suscribe solo, sin necesitar aquel refrendo. 
durante treinta años de los que han quedado cerca de un centenar de piezas ${ }^{98}$. Sus documentos siguen iluminando un área geográfica tan amplia como la de sus predecesores, extendiéndose a territorios tan lejanos como Teverga, Langreo, Allande o Villaviciosa. A lo sumo las relaciones de testigos, todavía muy numerosos, sugieren que algún oficial suyo trabajó en su nombre en territorios limítrofes como Siero ${ }^{99}$, pero cada vez es más dudoso que el propio notario haya actuado fuera de la jurisdicción ovetense, según se desprende de esas mismas listas de testigos.

Y a medida que su actividad se estabiliza en la ciudad, su oficina se va desarrollando, constatándose la existencia, por un lado, de hasta tres tenentes de su notaría, y por otro de una veintena de escribanos grossatores y registratores. En los tipos documentales tradicionales, la forma diplomática continuaba en buena medida la práctica aprendida en sus primeros años, cuando trabajaba para Rodrigo Martínez: documentos privados en pergamino, redactados mayormente en el romance asturiano y aún con formulación subjetiva. Los otorgantes expresan haber mandado hacer la carta y haberla oído leer en concello cuando añaden sus signos. Con todo, algunas cláusulas heredadas empiezan a caer del formulario al uso: la ceremonia de beber el vino se refleja ya muy raramente desde fines de los sesenta; la de romper el cántaro solo se incluye en un documento ${ }^{100}$. Por el contrario, la novedosa práctica del registro se muestra bastante habitual, sobre todo en compraventas, a través de la abreviatura $R$ puesta al final del documento, y en algún caso particular de la referencia explícita a que la carta se registró.

Por su parte, los tipos nuevos expresan usos diplomáticos antes desconocidos. Avanzan progresivamente hacia la forma de acta algunos testimonios y traslados redactados en su notaría ${ }^{101}$. Su formulación comienza a dar lugar a algunas novedades como las cláusulas de renuncia que emplea en una decena de $\operatorname{casos}^{102}, \mathrm{y}$ asimismo empiezan a aparecer tipos documentales raros hasta entonces como los testamentos ${ }^{103}$. Nicolás Yáñez nunca califica de instrumento público los trabajos emanados de su notaria, y la rogatio aparece principalmente en aquellos tipos documentales para los que el formulario tradicional no ofrecía soluciones: sobre todo traslados, también alguna avenencia. Era su nueva y permanente calificación como notario público la que abría la puerta a la entrada en Asturias de toda la teoría notarial.

98. Véase también, en su momento, la tesis doctoral de O. Rodríguez Fueyo sobre los primeros notarios públicos de la ciudad de Oviedo.

99. AMSPO.FSV.773.

100. AMSPO.FSV.1073. Y sin embargo debía seguir practicándose: se recoge en la nota dorsal de un documento de 1273, pero no llegó a formalizarse en la grosa del documento (AHN. Cl.1601.3).

101. Los primeros testimonios empiezan también con la invocación verbal y la notificación habitual connosçida cosa sea a quantos esta carta vieren... (ACO, ms. 4, fol. 143v). A partir de ahí la invocación desaparece y la comparecencia del notario ocupa el centro de la escena (ACO.B.4.18, Miguel Vigil. Ayuntamiento de Oviedo, $\mathrm{n}^{\circ} 12$; AHN.Cl.1602.15). Ya un caso de 1269 se abre con la data (ACO.A.8.13).

102. Reconocimiento de pago de una deuda en 1264 (AHN.Cl.1600.11bis), compraventas repartidas entre 1265 y 1290 (AMSPO.FSV.759, 771, 772, 774), anulación de demandas en 1265 y 1272 (AMSPO.FSV.903 y 1012), avenencia en 1279 (Miguel Vigil. Ayuntamiento de Oviedo, $\mathrm{n}^{\circ} 43$ ).

103. AMSPO.FSV.1018, ACO.A.10.6. 
El segundo ámbito de actuación de Nicolás Yáñez es el judicial, conocido únicamente a través del mandato de ejecución de una sentencia del año $1270^{104}$. Lo intitulan Fernán Díez y Lope Peláez, jueces de Oviedo, que tras un largo expositivo en el que describen demanda, sentencia y apelación, insertan el documento por el que Alfonso X confirmó su sentencia en primera instancia, y se dirigen a merinos, jueces y justicias estableciendo que ejecuten el pago sobre los bienes de la condenada. El documento fue escrito personalmente por Nicolás Yáñez, per mandado de los jueces, y resultó validado por el sello del concejo de Oviedo.

Y así se enlaza con el tercer ámbito de actuación de este primer notario público de Oviedo y de Asturias. Al igual que hiciera su predecesor, Nicolás Yáñez parece compaginar su actividad al servicio de los particulares y de la justicia con el trabajo como escribano de concejo. También como en el caso de Rodrigo Martínez, los testimonios que han quedado de su labor para el municipio son muy escasos. No se puede excluir que sea suya la mano anónima que pone por escrito las ordenanzas de $1262^{105}$, pero no hay duda de que es él quien suscribe en persona -intitulándose de nuevo como notario del rey póblico en Oviedo-dos documentos de gestión de propiedades concejiles cuya ejecución material fue obra de amanuenses. Por el primero de ellos, en 1264, el concejo cedía en arrendamiento el derecho exclusivo de vender cueros y cabruñas; por el segundo, cinco años después, se procedía al aforamiento de una heredad municipal ${ }^{106}$. Ambos añaden el sello concejil a la suscripción de Nicolás Yáñez; el segundo de ellos, incorpora además quirografía y el sello del abad de San Vicente de Oviedo.

En suma, de la actividad de Rodrigo Martínez a la de Nicolás Yáñez la mayor diferencia estriba en la autoridad que invocan: si el primero se remitía al concejo, el segundo se hace tributario del rey. No sería de extrañar que el cambio se hubiera producido en una situación conflictiva: por los mismos años la institución catedralicia se dota también de un scriván del cabildo cuyas primera actuación conocida data de 1262 en una compraventa ${ }^{107}$. De hecho es la única ocasión en la que tenemos constancia de que haya puesto por escrito un negocio de naturaleza semejante. A partir de entonces, y aunque perdura en activo durante bastantes años, se dedica esencialmente a la formalización de contratos agrarios refrendados por el sello del cabildo. Quizá haya que ver en estos hechos un nuevo síntoma de que, a principios de los sesenta, la autoridad sobre el nombramiento de escribanos con reconocimiento público era objeto de disputa, y la Iglesia ya rechazaba a los escribanos de concejo, de los que antes se había servido, o a los nuevos notarios. Durante un tiempo serán frecuentes los documentos otorgados por instituciones

104. Ruiz de la Peña. "Facer justicia", no 6.

105. Miguel Vigil, Ayuntamiento de Oviedo, $\mathrm{n}^{\mathrm{o}} 29$.

106. Ibid., nos. 30,34 .

107. ACO.A.8.4 y 6. Sobre el mismo, v. T. de la Roz Sánchez. "Simón Pérez, primer escribano del cabildo de la catedral de Oviedo (1262-1287)", Historia. Instituciones. Documentos 42 (2015), pp. 341-366, así como su tesis doctoral en elaboración sobre los escribanos públicos del cabildo de Oviedo en el siglo XIV. 
eclesiásticas cuyo principal elemento de validación es el sello, como si evitasen recurrir a los escribanos públicos de nombramiento real ${ }^{108}$.

Sin embargo el poder real se impuso en Asturias a la hora de acaparar el nombramiento de escribanos públicos, vinculándolos con frecuencia a núcleos urbanos de reciente creación. A partir de la década de los setenta, el proceso de fundación de pueblas regias en el territorio asturiano adquiere un impulso definitivo ${ }^{109}$, y la aparición de notarios públicos en las jurisdicciones reales sigue un ritmo similar.

En las de más antigua creación, los escribanos de concejo documentados en el capítulo anterior resultan reemplazados por notarios públicos de nombramiento regio, siendo el caso más significativo el de la puebla de Grado ${ }^{110}$. Martín Rodríguez, a quien hemos visto como escribano de aquel concejo en un capítulo anterior, ve reducida su categoría en 1270 a la de amanuense al servicio de Rodrigo Alfonso, que es el nuevo notario público nombrado por el rey. En cualquier caso es muy interesante observar que aunque aquél actúa per mandado de éste, sigue empleando el viejo signo que usaba cuando era escribano de concejo. En otros casos, aunque la información es menor, el camino parece similar. En el extenso realengo asturiano de fines del siglo XIII, la práctica totalidad de las villas nuevas va a ver documentado su notario público de nombramiento real antes del filo de $1300^{111}$.

Paralelamente, dichos notarios públicos tienen un papel importante en la confección de los pocos documentos concejiles y judiciales que han llegado a nuestros días. El concejo de Oviedo siguió recurriendo a ellos para una parte de sus documentos $^{112}$. Pero ahora el mejor ejemplo es el de la villa de Avilés, donde existen notarios públicos desde 1273 que pronto alcanzan el modesto número de dos ${ }^{113}$. Allí el concejo pasa de recurrir a amanuenses anónimos o identificados simplemente con su nombre ${ }^{114}$ a ceder la redacción de los documentos concejiles al notario público, al menos para la confección de algunos tipos documentales ${ }^{115}$. El ejemplo más evolucionado es el acuerdo que en 1289 suscribieron los concejos de Oviedo y Avilés ${ }^{116}$. A diferencia de los anteriores ${ }^{117}$, donde prevalecían los sellos, aquí el diploma fue autorizado por la suscripción de dos notarios públicos, uno

108. Aunque sería necesario un estudio sistemático, ha llamado la atención sobre esta particularidad Antuña Castro. Notariado en el señorio de los obispos, p. 50.

109. J.I. Ruiz de la Peña. Las polas asturianas en la Edad Media. Estudio y diplomatario. Oviedo, 1981 .

110. Seguimos el estudio de G. Fernández Ortiz. "La práctica notarial en el concejo de Grado (Asturias) durante el siglo XIII. De los escribanos rurales al notariado público". En prensa.

111. Ya fueron documentados por Sanz Fuentes. "Documento notarial y notariado en la Asturias del siglo XIII", pp. 258-280.

112. No se cita en las ordenanzas de 1274 , pero sí en el acuerdo que establece ese mismo año con sus alfoceros de Nora a Nora (Miguel Vigil. Ayuntamiento de Oviedo, $\mathrm{n}^{\circ} 20$ ) y, por primera vez en unas ordenanzas, en las de los cueros de 1287 (ibid., $\mathrm{n}^{\circ}$ 61).

113. El primero en AMSPO.FSV.817. Cfr. Sanz Fuentes e.a. Concejo de Avilés, pp. 34-35.

114. Así en la carta de vecindad de 1266 (ibid., $\mathrm{n}^{\mathrm{o}} 11$ ).

115. Así en el extenso número de cartas de vecindad que se conservan desde 1280 (ibid., nos. 16, $18,19,21,24,27,34)$, en el arrendamiento del diezmo de la renta de la madera en 1286 (ibid. $\mathrm{n}^{\circ} 35$ ), o en un poder de 1289 (ibid., $\mathrm{n}^{\mathrm{o}} 42$ ).

116. Ibid., $\mathrm{n}^{\mathrm{o}} 43$.

117. Por ejemplo el que alcanzan en 1282 , ibid., $\mathrm{n}^{\mathrm{o}} 25$. 
ovetense y otro avilesino, señal clara de que la figura del notario se identificaba estrechamente con la del escribano de concejo, y actuaba como fedatario en beneficio de su comunidad.

Eso no obsta para que, salvo este último, el concejo de Avilés valide todos los documentos citados con la aposición de su sello. Y es que el sello, en lo que resta del siglo XIII, sigue siendo el elemento definitorio del documento concejil ${ }^{118}$. Son muchos más, por tanto, aquellos documentos otorgados por el concejo o sus oficiales que callan sobre su autor material y se remiten directamente al sello. Así ocurre en documentos de relación establecidos con otros concejos, acuerdos como la hermandad de La Espina constituida en 1277 entre los concejos de Avilés, Pravia, Grado, Salas, Somiedo, Valdés, Tineo, Cangas y Allande ${ }^{119}$, o misivas como la remitida en 1283 por el concejo de Maliayo al de Oviedo ${ }^{120}$. El hecho de que cada uno de aquellos nueve municipios dispusiera de sello propio traza un mapa completo del área centro-occidental de la región y demuestra la generalización del sistema. Tanto es así que encontramos nuevos municipios rurales que también lo incorporan ${ }^{121}$. En cuanto a su uso, y al igual que ocurría en la época anterior, seguimos viendo que los particulares piden su aposición para mayor firmeza de asuntos privados $^{122}$.

En fin, el ámbito de la documentación judicial en instancias locales sigue una evolución coherente con lo descrito. En 1288 un juez de Oviedo dicta sentencia que, a petición de la parte ganadora, fue redactada ante el tenente de una notaría ovetense y validada con el sello del concejo de la localidad ${ }^{123}$. Es cierto que los merinos regios mantuvieron en estos años oficinas que aparentan estar bien organizadas, que emplean sello propio e incorporan nota de registro al menos desde $1285^{124}$. Pero en el ámbito local los jueces recurrían al sello concejil y, según atestigua el caso anterior, los documentos judiciales empezaban a extenderse ante notario público, según lo prescrito en la legislación alfonsí.

Fuera del dominio realengo, las cosas evolucionaban con mayor lentitud. En las jurisdicciones episcopales se aplican soluciones variadas al problema de dónde escriturar los negocios entre particulares ${ }^{125}$. Allí perdura más el recurso a los presbíteros rurales, pero también se observa la atracción de las nuevas prácticas cuando acuden al escribano de concejo de Oviedo, y más adelante a los notarios

118. Puede verse el estudio clásico de J. González. "Los sellos concejiles de España en la Edad Media”. Hispania 20 (1945), pp. 339-384.

119. Sanz Fuentes e.a. Concejo de Avilés, no 15.

120. Ibid., $\mathrm{n}^{\mathrm{o}} 26$.

121. En la montaña oriental, encontramos el del concejo de Cabrales añadido en 1265 a la carta de poder de una particular (AMSPO.FSV.772). Aparece el de Caso en 1272, cuando el monasterio de Eslonza estableció las cargas de sus vasallos de Soto y Velerda (Ruiz Asencio y Ruiz Albi. Eslonza, $\left.n^{\circ} 259\right)$.

122. Hay noticia por ejemplo de la aposición del sello de Allande a una carta de obligación en 1270 en Rodríguez Villar. Kalendas I, p. 398.

123. Sanz Fuentes e.a. Concejo de Avilés, no 39.

124. Así se observa ibid., nos. 29 y 38.

125. Seguimos aquí las observaciones de Antuña Castro. Notariado en el señorío de los obispos, p. 46. 
públicos de los concejos realengos limítrofes. Es interesante subrayar que, a partir de 1275, el notario público de la puebla episcopal de Roboredo invoca la autoridad real $^{126}$, señal de que el monarca trataba de imponerse incluso en las jurisdicciones señoriales; siete años más tarde, ya aparece como notario del rey e del obispo ${ }^{127}$. En fin, hay que esperar a 1292 para encontrar un notario público de nombramiento episcopal en Las Regueras. En cualquier caso, la importancia del sello seguía incólume, como se observa en 1283 cuando unos particulares solicitan al juez la aposición a una compraventa del sello del pequeño concejo de Proaza ${ }^{128}$.

En los monasterios, las cosas no son muy distintas. Oscos logró hacerse muy pronto con la capacidad de nombrar notario público. Cornellana sigue adquiriendo porciones de la parroquial de Villazón, y quien se encarga de ponerlas por escrito en 1259-61 es el capellán de Cornellana ${ }^{129}$, reemplazado en los años setenta por un escribano que no invoca autoridad alguna; hay que esperar a 1297 para encontrar el primer documento notarial de este largo proceso de adquisiciones ${ }^{130}$.

En definitiva, el debilitamiento del poder real de finales del siglo XIII parece haber ralentizado la imposición del notariado de cuño romanista, permitiendo a otros señoríos participar en su nombramiento y haciendo perdurar durante algún tiempo usos diplomáticos más tradicionales. Sin embargo el camino quedaba abierto y se mostraba atractivo. En 1309, Fernando IV se dirigía a una extensa nómina de concejos de realengo asturianos, recordándoles su exclusivo derecho de nombramiento de notarios públicos ${ }^{131}$. Con ello mostraba su interés en el control de una institución que se estaba convirtiendo en una pieza esencial del engranaje del poder local. Y aunque en algunas circunscripciones rurales perduraría un notariado peculiar, en algunos casos durante siglos ${ }^{132}$, las villas se habían convertido en su medio natural.

\section{Conclusiones}

Sobre una arraigada tradición diplomática altomedieval que se basaba en escribanos eclesiásticos, la aparición de las villas medievales asturianas conllevó un cambio decisivo en la identidad de los rogatarios de los documentos.

El proceso se caracteriza por su lentitud. Aunque el aforamiento de Oviedo y Avilés se remonta a las inmediaciones del 1100, durante más de un siglo los clé-

126. Álvarez Castrillón. Oscos, nos. 183, 186, 188, 190, 191, 192, 194, 198, 199, 200, 203.

127. ACO, Libro de los privilegios, $16 \mathrm{v}-18 \mathrm{v}$, tomado de Antuña Castro. Notariado en el señorio de los obispos, p. 48.

128. M.J. Jiménez Suárez. Colección documental del monasterio de San Andrés de Espinareda (1043-1428). León, 2005, nº 48.

129. Fernández de Viana. "Cornellana", nos. 11-15.

130. Ibid., nos. 16-19.

131. Miguel Vigil. Ayuntamiento de Oviedo, $\mathrm{n}^{\circ} 88$.

132. F.J. Álvarez Carbajal. El registro del notario Martín Fernández de Ruiforco (1468). Un escribano público en el condado de Luna, Sevilla, 2014; E. Rodríguez Díaz. Notas y cuadernos de notas de los Piñán, escribanos públicos de Sajambre (1659-1721), Uviéu, 2015. 
rigos siguen protagonizando la producción de los documentos que se conservan. A principios del siglo XIII aún se muestran pioneros mediante la organización de la cancillería episcopal, la redación de obituarios y de nuevas modalidades de cartularios, el empleo nuevo de contratos agrarios y la difusión del sello en algunas de las instituciones más poderosas. Comienza a extenderse el romance, y en esa época destaca sobre todo el presbítero Pedro Bono, que desde la ciudad de Oviedo ilumina la vida urbana y la de un extenso entorno rural como redactor de un abultado número de documentos.

Cuando empieza el segundo tercio del siglo XIII se verifican algunos importantes cambios. Son más evidentes en el concejo de Oviedo, fortalecido por Alfonso IX, que pronto comienza a sellar sus documentos y respalda la actuación de una oficina de escritura en torno a Rodrigo Martínez, escriván del concello. Conocido sobre todo por su actividad al servicio de los particulares, su mano parece estar también detrás de los pocos documentos propiamente concejiles que se conservan. Pero más allá de Oviedo, las décadas centrales del siglo XIII contemplan la difusión del sello diplomático en varios concejos del territorio asturiano, y la aparición en algún otro de nuevos escribanos de concejo. En su praxis, se consolida el empleo de la lengua romance y se verifica la existencia de dos momentos en la redacción de los documentos. Por los mismos años, la única oficina de escritura de titularidad regia que se atisba en la región es la de los merinos mayores, que validan regularmente con sello y parecen disponer de algún amanuense a su servicio.

La culminación del cambio se produce en el último tercio de la centuria, y viene motivada por la intervención de los monarcas en el nombramiento de los escribanos que actúan con respaldo público a escala local. En efecto, a partir de 1263 comparece en la documentación el primer notario público del rey en Oviedo, al que siguen en las décadas sucesivas otros oficiales homólogos en muchas jurisdicciones asturianas. A su servicio se desarrollan oficinas notariales jerarquizadas en las que se van extendiendo las prácticas y los caracteres formales propios del notariado público. En estas primeras décadas de su existencia, se observa que no solo se ocupan de la escrituración de los documentos privados, sino que también desempeñan funciones de escritura al servicio de la justicia y del concejo.

\section{BIBLIOGRAFÍA}

Álvarez Arias, Celia. Documentos orixinales del monesteriu de San Vicente d'Uviéu, I (1231-1238). Uviéu, 2008.

Álvarez Carbajal, Francisco Javier. El registro del notario Martín Fernández de Ruiforco (1468). Un escribano público en el condado de Luna, Sevilla, 2014.

Antuña Castro, Roberto. Notariado y documentación notarial en el área central del señorio de los obispos de Oviedo (1291-1389). Tesis doctoral inédita, Universidad de Oviedo, 2014.

Bono Huerta, José. Historia del Derecho Notarial español, (Vol.I-1). Madrid, 1979. 
Calleja Puerta, Miguel. "Un privilegio de Fernando III al concejo de la puebla de Tineo (1232)". En Fernando III y su tiempo (1201-1252). León, 2003, pp. 395-419.

—. "Un escribano ovetense de principios del siglo XIII: el presbítero Pedro Bono". En Orígenes de las lenguas romances en el reino de León, Siglos IX-XII. León, 2004, pp. 465-490.

—. "De la visigótica a la carolina en los documentos del archivo de San Vicente de Oviedo: la escritura de Dominicus y Pelagius". En J.A. Fernández Flórez y S. Serna (coords.). Paleografía I. La escritura en España hasta 1250. Burgos, 2008, pp. 189-200.

—. "El fuero de Avilés de 1155, original extracancilleresco de Alfonso VII". En J.I. Ruiz de la Peña, M.J. Sanz Fuentes y M. Calleja Puerta (eds.). Los fueros de Avilés y su época. Oviedo, 2012, pp. 431-461.

Camino Martínez, Carmen del. "Escritura y elaboración formal de los Fueros de Avilés”. En J.I. Ruiz de la Peña, M.J. Sanz Fuentes y M. Calleja Puerta (eds.). Los fueros de Avilés y su época. Oviedo, 2012, pp. 405-430.

Casado Lobato, Concepción. Colección diplomática del monasterio de Carrizo, León, 1983.

Corral García, José Luis. El escribano de concejo en la Corona de Castilla (siglos XI al XVII). Burgos, 1987.

D'Emilio, James. "Writing is the precious treasury of memory. Scribes and notaries in Lugo (1150-1240)". En H. Spilling (ed.). La collaboration dans la production de l'écrit médiéval. Paris, 2003, pp. 379-403.

Fernández Conde, Francisco Javier, Torrente Fernández, Isabel y de la Noval, Guadalupe. El monasterio de San Pelayo de Oviedo, I. Oviedo, 1978.

Fernández Flórez, José Antonio y Herrero de la Fuente, Marta. Colección documental del monasterio de Santa María de Otero de las Dueñas, II (1109-1300) e indices. León, 2005.

Fernández Mier, Margarita. Documentos del monesteriu de Balmonte (sieglu XIII). Uviéu, 1995.

Fernández Ortiz, Guillermo. "La práctica notarial en el concejo de Grado (Asturias) durante el siglo XIII. De los escribanos rurales al notariado público”. En prensa.

Fernández de Viana y Vieites, José Ignacio. "Pergaminos del monasterio de Cornellana (Asturias) en el archivo de San Payo de Antealtares (Santiago)". Asturiensia Medievalia 4 (1981), pp. 297-399.

Floriano Cumbreño, Antonio C. El libro registro de Corias, 2 vols., Oviedo, 1950.

- Colección diplomática del monasterio de Belmonte. Transcripción y estudio. Oviedo, 1960.

Floriano Llorente, Pedro. Colección diplomática del monasterio de San Vicente de Oviedo. Oviedo, 1968.

González, Julio. "Los sellos concejiles de España en la Edad Media". Hispania 20 (1945), pp. 339-384. 
Hoyos González, Carmen de. Rodrigo Martínez, escribano del concejo de Oviedo. Tesis de licenciatura inédita, Universidad de Oviedo, 2013.

Jiménez Suárez, María Jesús. Colección documental del monasterio de San Andrés de Espinareda (1043-1428). León, 2005.

López Alsina, Fernando. "Galicia en los siglos XII-XIII: notariado, documentos y cultura literaria”. En A.I. Boullón Agrelo (ed.). Na nosa lyngoage galega. A emerxencia do galego como lingua escrita na Idade Media. Santiago de Compostela, 2007, pp. 53-67.

Martín Fuertes, José Antonio. "Los notarios en León durante el siglo XIII", en Notariado público y documento privado: de los orígenes al siglo XIV. Actas del VII Congreso Internacional de Diplomática. Valencia, 1989, pp. 597-613.

—. "Notarios públicos y escribanos del concejo de León en el siglo XIV". Archivos Leoneses 38 (1984), pp. 7-30.

Martínez Sopena, Pascual. "El mercado en la España cristiana de los siglos XI y XII", Codex Aquilarensis 13 (1998), pp. 121-142.

Miguel Vigil, Ciriaco. Colección histórico-diplomática del ayuntamiento de Oviedo. Oviedo, 1889.

Rodríguez Díaz, Elena. El libro de la Regla Colorada de la catedral de Oviedo. Oviedo, 1995.

- Notas y cuadernos de notas de los Piñán, escribanos públicos de Sajambre (1659-1721), Uviéu, 2015.

Rodríguez Fueyo, Olaya. "Nicolás Yáñez. El paso del prenotariado al notariado en Oviedo en el siglo XIII". En A. Castro Correa e.a. (eds.). Estudiar el pasado. Aspectos metodológicos de la investigación en Ciencias de la Antigüedad y de la Edad Media. Oxford, 2012, pp. 383-391.

Rodríguez Villar, Víctor M. Libro de regla del Cabildo (Kalendas I). Estudio y edición del manuscrito $n^{\circ} 43$ de la Catedral de Oviedo. Oviedo, 2001.

Rojas Vaca, María Dolores. "Los inicios del notariado en el reino de Castilla. Aportación a su estudio". Anuario de estudios medievales 31 (2001), pp. 329400.

Roz Sánchez, Tomás de la. "Simón Pérez, primer escribano del cabildo de la catedral de Oviedo (1262-1287)". Historia. Instituciones. Documentos 42 (2015), pp. 341-366.

Ruiz Asencio, José Manuel y Ruiz Albi, Irene. Colección documental del monasterio de San Pedro de Eslonza. I (912-1300). León, 2007.

Ruiz de la Peña, Juan Ignacio. "Sobre la fundación de la Pola de Allande y su carta puebla”. Boletín del Instituto de Estudios Asturianos 68 (1969), pp. 16-19.

—. Las polas asturianas en la Edad Media. Estudio y diplomatario. Oviedo, 1981.

- El comercio ovetense en la Edad Media. Oviedo, 1990.

—. "Facer justicia en una ciudad medieval: el concejo de Oviedo contra doña Loba". Boletín del Real Instituto de Estudios Asturianos 146 (1995), pp. 589-602.

—. "Epílogo. Los orígenes de la villa de Llanes". En M. Calleja Puerta. El fuero de Llanes. Edición crítica. Oviedo, 2003. 
Santos, M.J.A. "Os clérigos-notários em Portugal (séculos XI-XII)”. En Estudos de Diplomática Portuguesa. Lisboa-Coimbra, 2001, pp. 75-91.

Sanz Fuentes, María Josefa. "Documento notarial y notariado en la Asturias del Siglo XIII”. En Notariado público y documento privado: de los orígenes al siglo XIV, Valencia, 1989, pp. 245-257.

—. "Notas acerca del sello del concejo de Oviedo". Asturiensia Medievalia 6 (1991), pp. 171-176.

—. "Documentos del monasterio de San Pedro de Villanueva (ss. XII-XIII)". Estudis Castellonencs 6 (1994-1995), pp. 1333-1342.

—. "Documento y cancillería episcopal en Oviedo anterior a 1300". En Ch. Haidacher y W. Köfler (eds.). Die Diplomatik der Bischofsurkunde vor 1250. Innsbruck, 1995, pp. 467-482.

- . "Documentos medievales del monasterio de Santa María de Obona en la Chancillería de Valladolid". Revista de Filoloxía Asturiana 2 (2002), pp. 155-191.

- " "De la vida y de la muerte. Cuatro documentos asturianos del siglo XIII". Revista de Filoloxía Asturiana, 3-4 (2003-2004), pp. 241-254.

- . "De diplomática concejil castellana en la Edad Media. Una nueva propuesta de clasificación documental”. En P. Cherubini y G. Nicolaj (eds.). Sit liber gratus, quem servulus est operatus. Studi in onore di Alessandro Pratesi per il suo $90^{\circ}$ compleanno. Città del Vaticano, 2012, pp. 535-548.

—. Álvarez Castrillón, José Antonio y Calleja Puerta, Miguel. Colección diplomática del concejo de Avilés en la Edad Media (1155-1498). Avilés, 2011.

— y Calleja Puerta, Miguel. "La lengua de los documentos asturianos en los siglos X-XIII: del latín al romance". En La langue des actes. Actes du XIe Congrès internationale de Diplomatique (Troyes, jeudi 11-samedi 13 septembre 2003), en línea, http://elec.enc.sorbonne.fr/CID2003/calleja-puerta_sanz-fuentes

- y Calleja Puerta, Miguel. Litteris confirmentur. Lo escrito en Asturias en la Edad Media, Oviedo, 2005.

- y Ruiz de la Peña, Juan Ignacio. Colección diplomática del monasterio de San Vicente de Oviedo (siglos XIII-XV). I.1: 1201-1230. Oviedo, 1991.

Serrano, Luciano. Cartulario de San Vicente de Oviedo (781-1200). Madrid, 1929.

Torrente Fernández, Isabel. El dominio del monasterio de San Bartolomé de Nava (ss. XIII-XVI). Oviedo, 1982.

Viejo, Xulio. "Noticia d'un vecindariu d'Uviéu del sieglu XII", Revista de Filoloxía Asturiana 6-8 (2006-2008), pp. 467-473.

Fecha de recepción del artículo: septiembre de 2015

Fecha de aceptación y versión final: octubre de 2015 